\title{
An Online Tool for Estimating Evapotranspiration and Irrigation Requirements of Crops in South Carolina
}

\author{
José O. PAYero ${ }^{*}$ \\ AUTHOR: ${ }^{1}$ Irrigation Specialist, Clemson University Edisto Research and Education Center, Blackville, SC, 29817. \\ *jpayero@clemson.edu
}

\begin{abstract}
In recent years, there has been an increased interest in South Carolina regarding the amount of water used by different consumers, especially agricultural producers. This interest has sparked conversations among different stakeholders, including the media, policy makers, producers, scientists, and the general public, regarding the current state and future of water resources in the state. Central to these discussions, from the agricultural sector perspective, is the question of how much water producers really need to grow crops. The objective of this study was, therefore, to develop an online tool to use local South Carolina historic weather data to estimate daily and seasonal crop evapotranspiration and irrigation requirements for different crops. The overall goal was for the new tool to assist farmers and other stakeholders to better plan irrigation water allocations and management. Therefore, an interactive online tool called ETcCalc was created to address this objective. ETcCalc, which is freely available online (http://sccropwater.com), was developed using historic weather data; therefore, it is suitable as an irrigation planning tool rather than a real-time irrigation scheduling tool.
\end{abstract}

\section{INTRODUCTION}

In South Carolina, water use for irrigation is mostly unregulated compared with other states. Currently, only some areas of the state are classified as capacity use areas, where water users with the capacity to withdraw over 3 million gallons in any given month are required to obtain a permit. In recent years, there has been considerable controversy in South Carolina regarding the unregulated use of water for agriculture. This has motivated legislators to consider imposing additional regulations on water use in the state. For example, in 2017, the South Carolina Department of Health and Environmental Control conducted a series of public hearings aimed at expanding the classification of capacity use areas, which had mainly impacted coastal counties, to cover some inland counties in the state. Recent events suggest that new legislations and regulations on agricultural water use are to be expected in years to come.

One of the critical questions that will be asked when developing new water regulations will be how much water a farmer really needs to grow a specific crop at a specific location in South Carolina. The answer to this question is complex, because the amount of water used by a crop, known as crop evapotranspiration (ETc), is heavily dependent on the local weather conditions, which vary by time of day, by day of the year, and from year to year. Furthermore, the seasonal irrigation requirements, in addition to the water used by the crop, also depend on other factors, such as soil type, soil water content at the time of planting, efficiency of the irrigation system and, especially, effective rainfall during the crop growing season. The amount of effective rainfall and ETc during the crop growing season are the two most important components influencing the irrigation requirements of a crop. The amount of rainfall can easily be measured with rain gauges, but directly measuring ETc is difficult and expensive.

The traditional method of measuring ETc is by planting the crop inside a weighing lysimeter (Figure 1) and measuring the changes in lysimeter mass during a given time interval (Fisher, 2012; Payero \& Irmak, 2008; Schneider et. al., 1998). Changes in mass during relative short periods of time (hourly or daily) are assumed to be due to changes in water content of the soil inside the lysimeter box, which allow calculation of ETc. Lysimeters, however, are expensive to build, difficult to maintain, and fixed to a specific field.

In recent decades, micrometeorological methods, such as the eddy covariance (EC) method (Burba \& Anderson, 2007), have become popular among researchers because they offer accuracy and portability. EC systems are similar to a weather station, which can be installed in the middle of a 

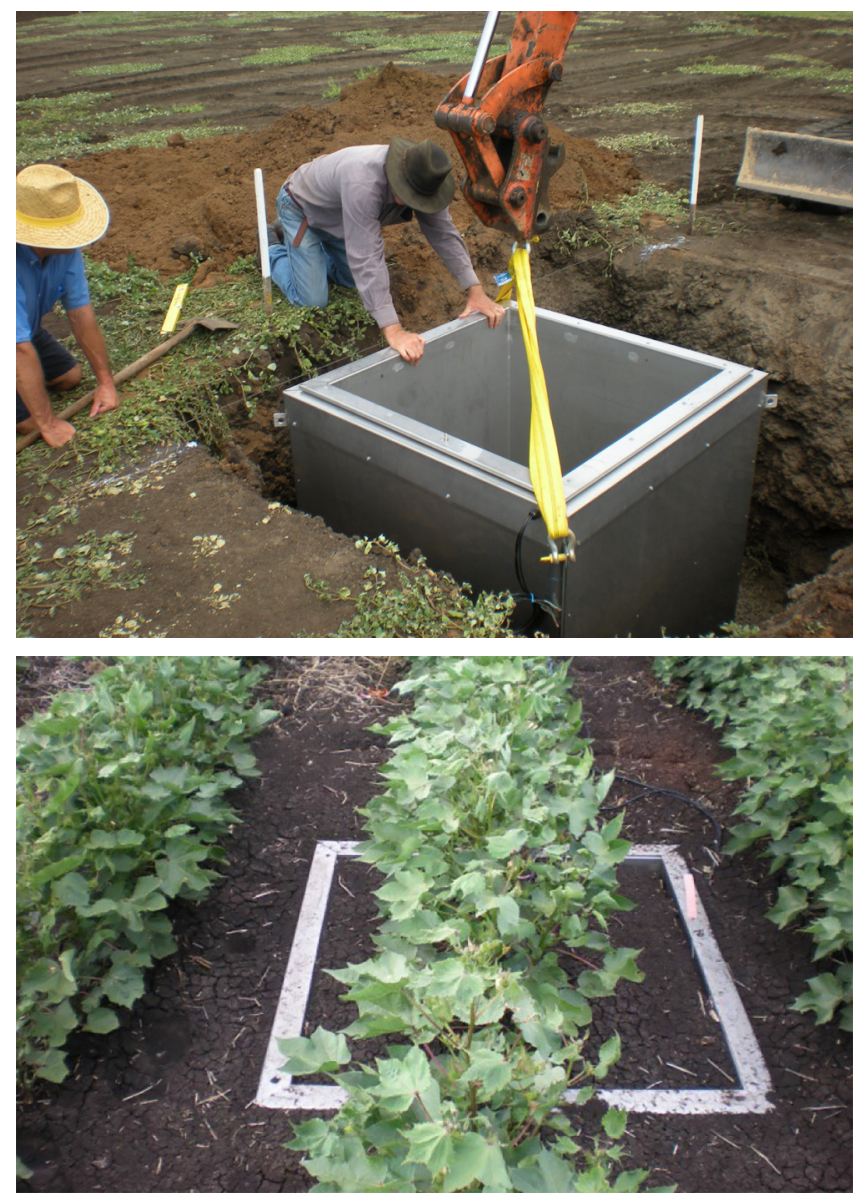

Figure 1. Lysimeter installation (top), and cotton crop planted on lysimeter (bottom).

field and can be moved to a different field as needed (Figure 2). The EC system, for example, can measure all of the components of the 1-dimensional energy balance equation,

$$
\mathrm{Rn}-\mathrm{G}=\mathrm{LE}+\mathrm{H},
$$

where $\mathrm{Rn}$ is net radiation, $\mathrm{G}$ is soil heat flux, $\mathrm{H}$ is sensible heat flux, and LE is latent heat flux (all in units of $\mathrm{W} \mathrm{m}^{-2}$ ). ETc is derived by converting LE to units of water depth (inches or millimeters). EC systems, however, are very expensive (around \$50,000 each), which severely limits their use to measure ETc outside a small number of research applications.

Although there is a long history of research on actual ETc measurements for different crops under different environments around the world (Tolk et al., 1998; Evett et al., 2009; Payero \& Irmak, 2013), there is always a need for more measurements to keep pace with the development of new crop varieties and with the introduction of crops to new environments. Actual ETc measurements are also needed to calibrate and fine tune methods to estimate ETc from weather variables. However, it would be impossible to have actual measurements for every crop and every location. In the absence of actual local measurements of ETc, the next best thing is to estimate ETc from local weather

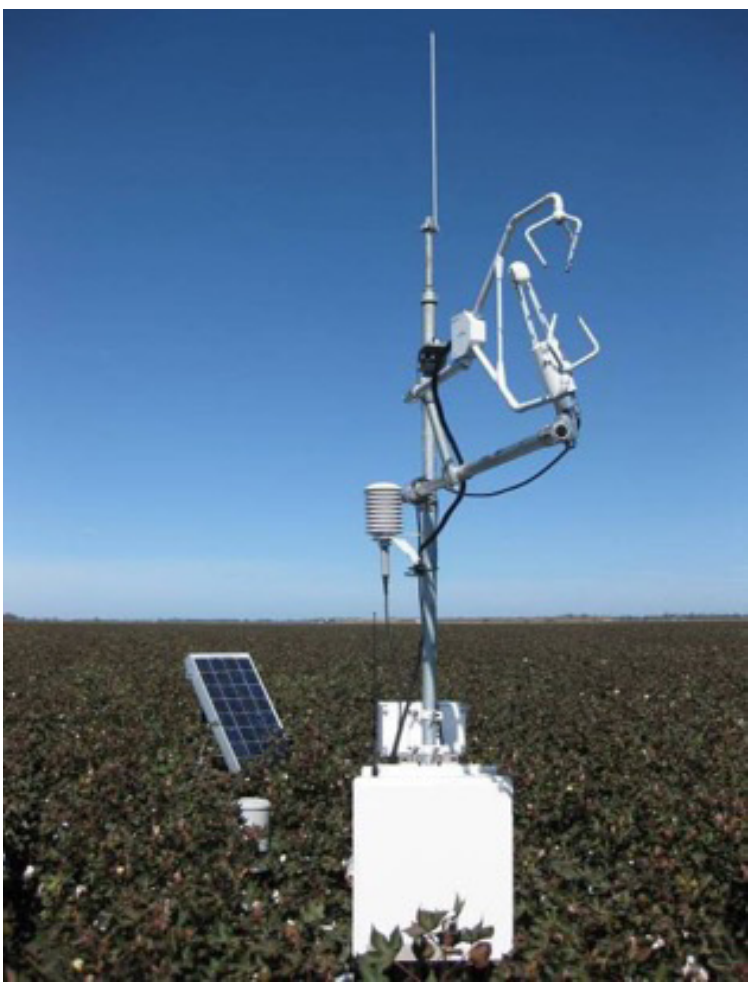

Figure 2. Eddy covariance system.

measurements. The objective of this study was, therefore, to develop an online tool to incorporate local South Carolina historic weather data to estimate daily and seasonal ETc and irrigation requirements for different crops. The overall goal was for the new tool to assist farmers and other stakeholders to better plan irrigation water allocation and management.

\section{METHODOLOGY}

An interactive online tool called ETcCalc was created to address this objective and is freely available at http:// sccropwater.com (Figure 3). Users can create a project and add up to 5 scenarios. Each scenario consists of a combination of a crop, location, planting date, and soil type.

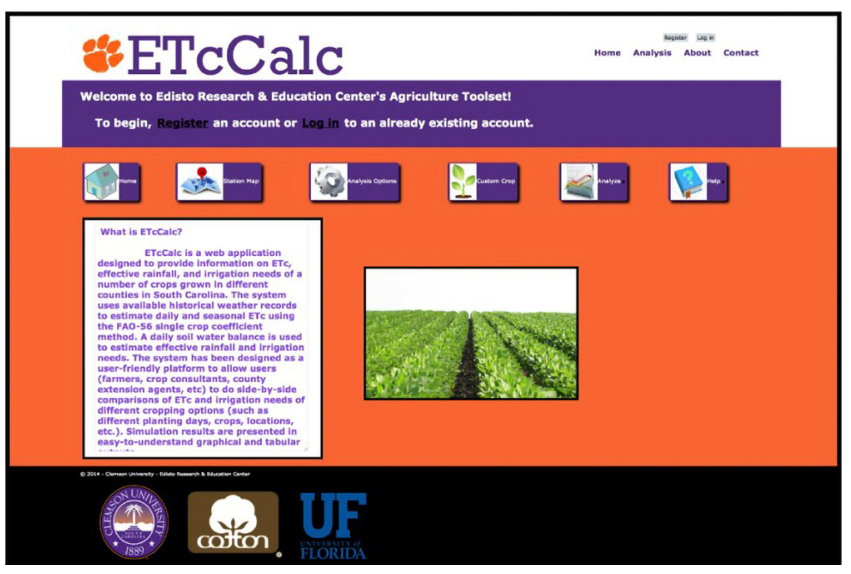

Figure 3. ETcCalc online tool. 


\section{An Online Tool for Estimating Evapotranspiration and Irrigation Requirements of Crops in SC}

For example, one scenario could include corn planted on April 10 in Aiken County in a silt loam soil, whereas another scenario could include soybean planted on June 12 in Anderson County in a sandy loam soil. The location can be chosen from a map (Figure 4) showing the weather stations in South Carolina that measure all the weather variables needed to calculate ETo using the Penman-Montheith method (solar radiation, air temperature, relative humidity, and wind speed). In 2014, we found that 696 weather stations were operating in South Carolina as part of the public weather station network, but only those stations shown in Figure 4 were equipped to measure all the variables needed to calculate ETo.

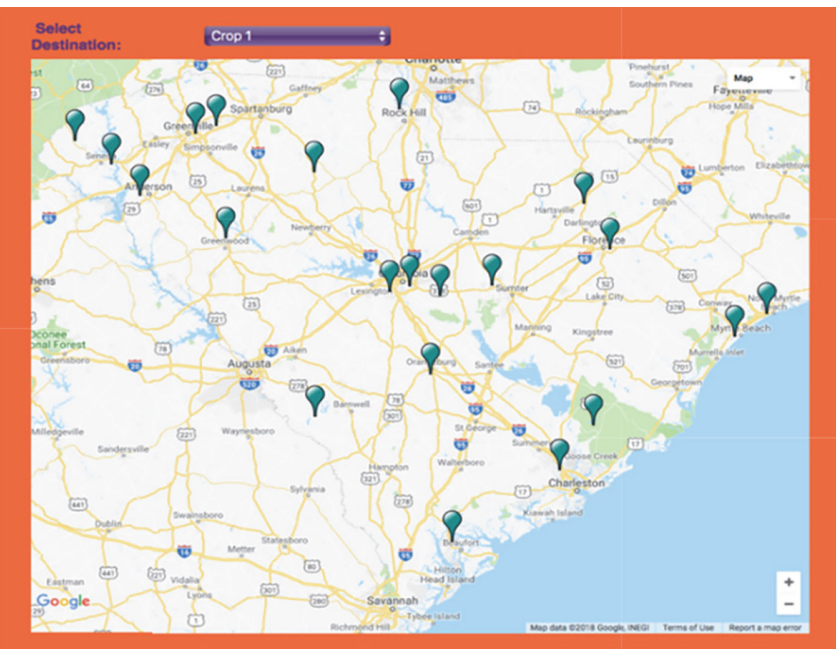

Figure 4. Location of weather stations in South Carolina included in ETcCalc.

After selecting the weather station from the map, the user can complete inputs for each scenario (Figure 5).

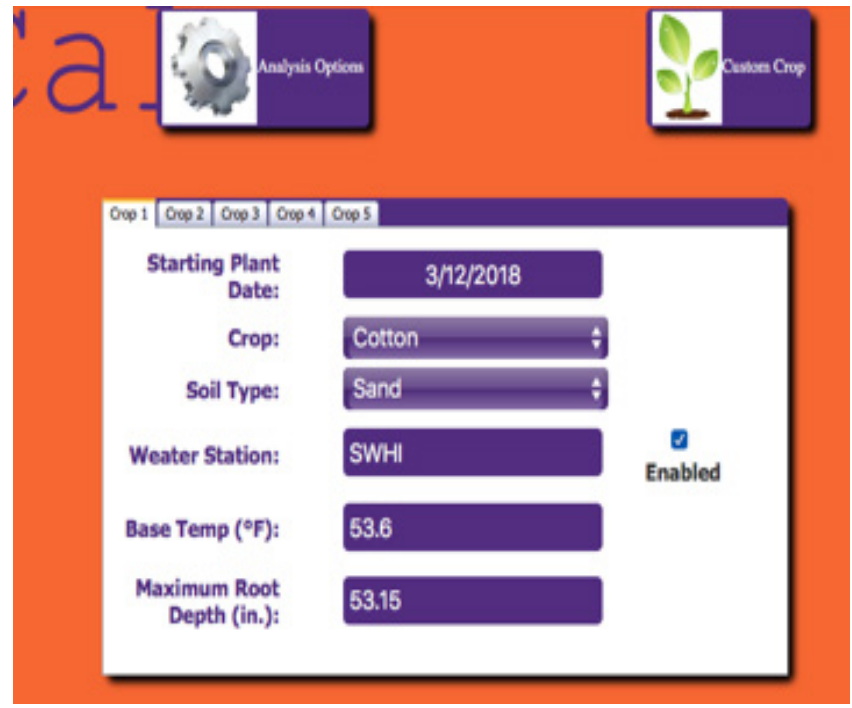

Figure 5. Inputs for each analysis scenario.

ETcCalc calculates daily ETc values for a crop with no water stress, using the Food and Agriculture Organization of
The United Nations' Paper 56 (FAO-56), "Guidelines for Computing Crop Water Requirements" (Allen et al., 1998) single crop coefficient procedure (Wright, 1982) as

$$
\mathrm{ETc}=\mathrm{Kc} \times \mathrm{ETo},
$$

where ETc is crop evapotranspiration (inch per day), $\mathrm{Kc}$ is the crop coefficient, and ETo is grass-reference evapotranspiration (inch per day). Historic daily ETo values for each of the weather stations were obtained from the North Carolina Climate Retrieval and Observations Network of the Southeast Database (CRONOS; http:// climate.ncsu.edu/cronos/), provided by the North Carolina Climate Office. These historic ETo values were then stored in a local database for easy access by ETcCalc. CRONOS calculates daily ETo values from weather data using the FAO56 Penman-Montheith method (Allen et al., 1998). ETcCalc provides default Kc and length of growth stage (LGS) values for 19 of the main crops in South Carolina, which have been taken from FAO-56. Actual measurements of daily water use, Kc, and LGS values of local crops are severely lacking in South Carolina. However, this subject is currently under investigation, and default $\mathrm{Kc}$ and LGS values in ETcCalc will be updated as more local data become available.

In addition to the default $\mathrm{Kc}$ and LGS values, ETcCalc allows users to create new crops or new crop varieties by providing adequate $\mathrm{Kc}$ and LGS values (Figure 6) for the initial, development, midseason, and late-season development stages, as defined by FAO-56 (Table 1).

Table 1. Definition of crop grow stages according to the Food and Agriculture Organization.

\begin{tabular}{ll}
\hline \multicolumn{1}{c}{ Crop Stage } & \multicolumn{1}{c}{ Stage Definition } \\
\hline Initial & Planting to 10\% ground cover \\
Development & 10\% Ground cover to effective full cover \\
Midseason & Effective full cover to start of maturity \\
Late Season & Start of maturity to harvest or full \\
& senescence \\
\hline
\end{tabular}

After the scenarios are specified in ETcCalc, an analysis can be performed. The resulting outputs would then show a side-by-side comparison of results from the different scenarios. ETcCalc calculates daily ETc values for every day in the specified historic weather record. Daily rainfall and ETc values are then used to conduct a daily soil water balance to estimate monthly and seasonal ETc, rainfall, effective rainfall (rain that is stored in the soil profile and is available to the crop), and rainfall deficit (ETc - effective rainfall). As a bonus, the tool also calculates daily growing degree days. ETcCalc presents results in both graphical and tabular formats. 


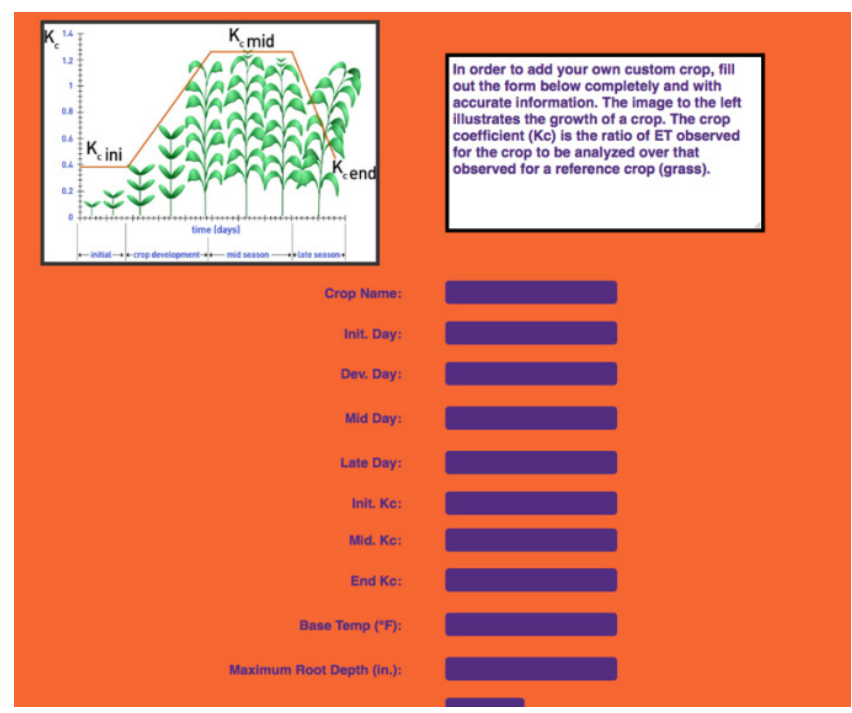

Figure 6. Inputs for each analysis scenario.

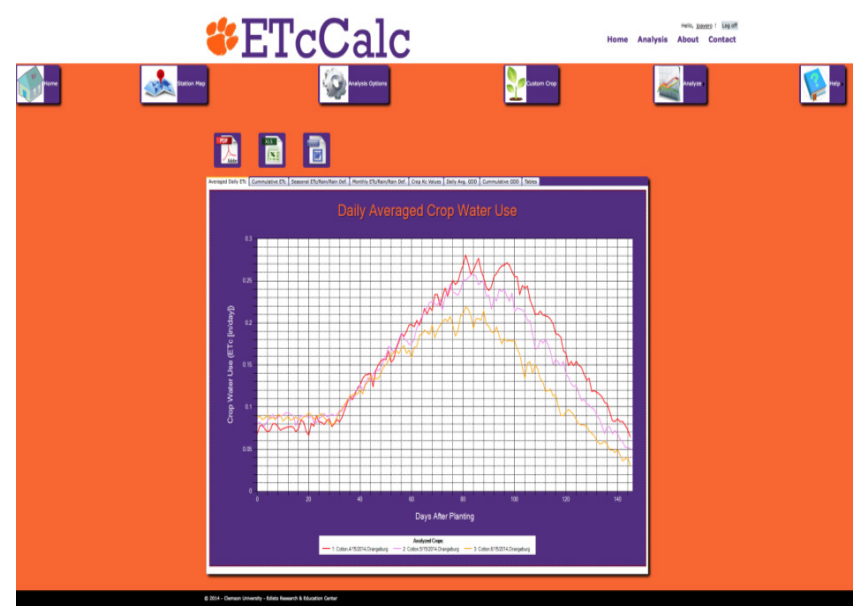

Figure 7. Daily crop evapotranspiration for cotton planted on 3 planting dates in Orangeburg, South Carolina.

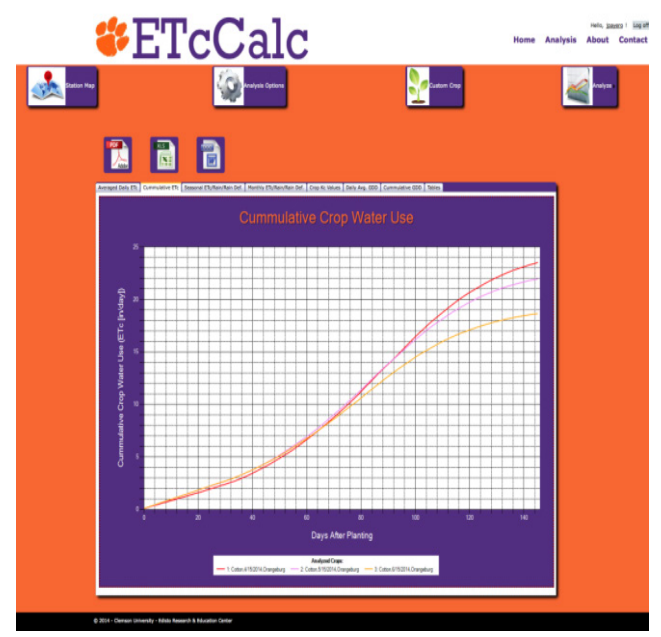

Figure 8. Daily cumulative crop evapotranspiration for cotton planted on 3 planting dates in Orangeburg, South Carolina.

\section{RESULTS}

In the following section, the outputs of the tool are illustrated by creating several scenarios comparing the impact of changing planting date for cotton.

An analysis with 3 scenarios was conducted to illustrate some of the outputs of ETcCalc. The scenarios included cotton planted on 3 different planting dates (April 15, May 15, and June 15) in Orangeburg, South Carolina. Figures 7 and 8 show the daily ETc and cumulative ETc for the 3 cotton planting dates. They show that planting date can have a big impact on both daily and seasonal ETc.

Figures 9 and 10 show the monthly and seasonal summaries of ETc, rain, effective rain, and rain deficit for each of the 3 planting dates. The seasonal summary (Figure 10) indicates that cotton planted earlier in the compared scenarios would have more ETc and less effective rainfall and would, therefore, require more irrigation.

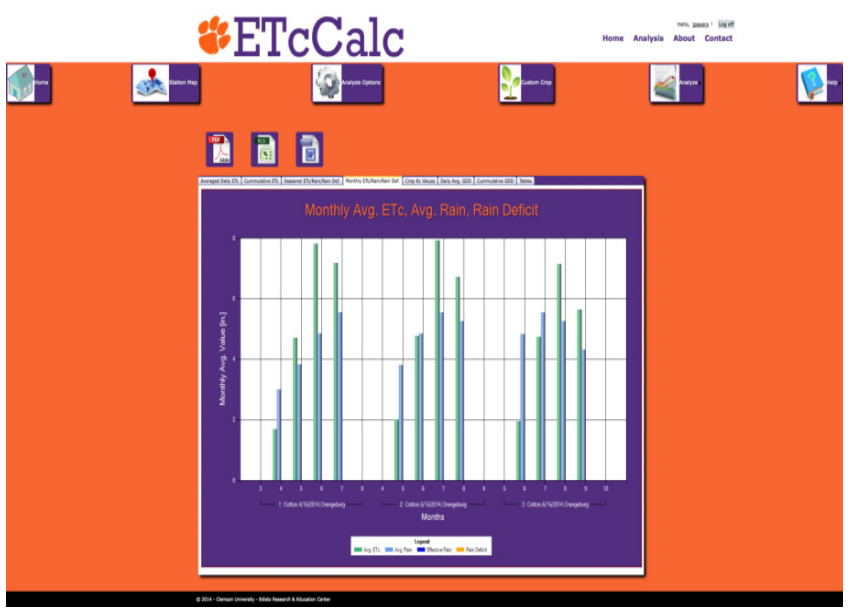

Figure 9. Monthly summary of crop evapotranspiration (ETC), rain, effective rain, and rain deficit for each of the 3 scenarios.

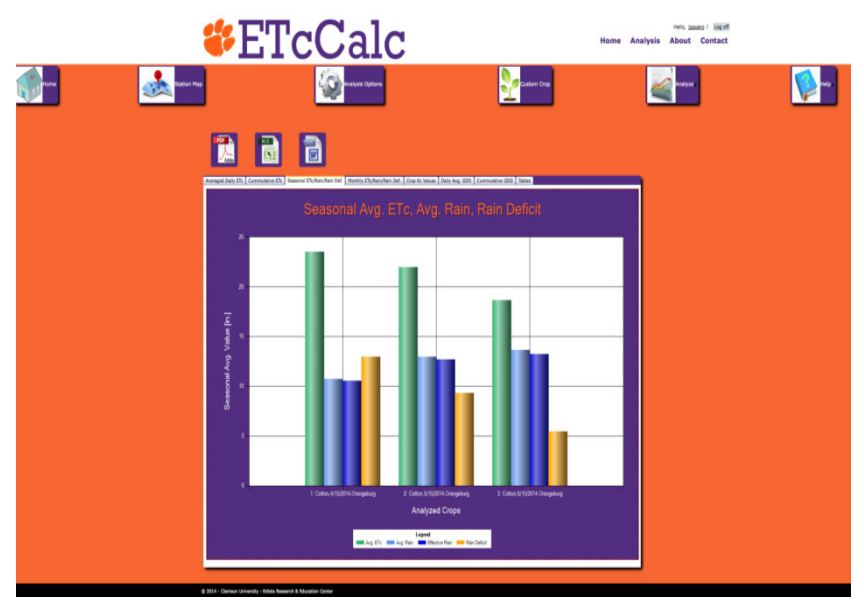

Figure 10. Seasonal summary of crop evapotranspiration (ETC; green), rain (light blue), effective rain (dark blue), and rain deficit (yellow) for each of the 3 scenarios. 


\section{An Online Tool for Estimating Evapotranspiration and Irrigation Requirements of Crops in SC}

\section{CONCLUSIONS}

ETcCalc is a tool that facilitates calculation of crop ETc and irrigation requirement for crops and allows side-by-side comparisons of different cropping scenarios. The ETcCalc tool was initially developed and made available online in 2014; therefore, the historic weather dataset after that year is not included. Currently, a new online tool is under development that will expand on the capabilities of ETcCal and will link directly to the CRONOS database for automatic download of the latest weather and ETo data. A couple of online tools for real-time irrigation scheduling, rather than for irrigation planning, are also currently under development. The new irrigation scheduling tools will use real-time weather data, rather than the static historic dataset used by ETcCalc. One of the tools is being designed to use real-time weather data from CRONOS, and the other will use data that come from Weather Underground (www.wunderground.com).

\section{ACKNOWLEDGEMENTS}

This is Technical Contribution Number 6640 of the Clemson University Experiment Station. This material is based upon work supported by U.S. Department of Agriculture, National Institute of Food and Agriculture, under Project Number SC-1700540. The author acknowledges Christopher Harvey for developing the computer code and the partial funding provided by the South Carolina Cotton Board.

\section{LITERATURE CITED}

Allen RG, Pereira LS, Raes D, Smith M. 1998. Crop evapotranspiration: guidelines for computing crop water requirements (FAO irrigation and drainage paper 56).

Rome (Italy): Food and Agriculture Organization of the United Nations. http://www.fao.org/docrep/X0490E/ X0490E00.htm.

Burba GG, Anderson D. 2007. Introduction to the eddy covariance method: general guidelines, and conventional workflow. Lincoln (NE): Li-Cor Biosciences.

Evett SR, Mazahrih NT, Jitan MA, Sawalha MH, Colaizzi PD, Ayars JE. 2009. A weighing lysimeter for crop water use determination in the Jordan Valley, Jordan. Trans. ASABE, 52(1):155-169.

Fisher DK. 2012. Simple weighing lysimeters for measuring evapotranspiration and developing crop coefficients. Int. J. Agric. Biol. Eng. 5(3): 35-43.

Payero JO, Irmak S. 2008. Construction, installation, and performance of two repacked weighing lysimeters. Irrigation Sci. 26(2):191-202.

Payero JO, Irmak S. 2013. Daily energy fluxes, evapotranspiration and crop coefficient of soybean. Agric. Water Manag. 129:31-43.

Schneider AD, Howell TA, Moustafa ATA, Evett SR, Abou-Zeid W. 1998. A simplified weighing lysimeter for monolithic or reconstructed soils. Appl. Eng. Agric. 14(3):267-274.

Tolk JA, Howell TA, Evett SR. 1998. Evapotranspiration and yield of corn grown on three High Plains soils. Agron J. 90:447-454.

Wright JL. 1982. New evapotranspiration crop coefficients. J. Irrigation Drain. Div. ASCE. 108:57-74. 